\title{
Avaliação de Acessibilidade Digital para Pessoas com Deficiência Motora em Repositórios Educacionais Abertos
}

\section{Title: Assessment of Digital Accessibility for People with Motor Disabilities in Open Educational Repositories}

Edna de Souza

Universidade Federal de Lavras

souzabrochado@gmail.com

\author{
Neumar Malheiros \\ Departamento de Ciência da Computação \\ Universidade Federal de Lavras \\ neumar@dcc.ufla.br
}

\begin{abstract}
Resumo
Na era da sociedade da informação, tornou-se impreterível considerar a importância das ações voltadas para a acessibilidade digital, como forma de lidar com as barreiras que impactam na inclusão digital das pessoas com deficiência. O presente trabalho tem por finalidade avaliar dois Repositórios Educacionais Abertos, o Portal Domínio Público e o Portal do Professor, para verificar se eles atendem as recomendações do "eMAG - Modelo de Acessibilidade em Governo Eletrônico”. Em particular, são consideradas apenas as recomendações que dizem respeito às pessoas com deficiência motora. Em relação ao método de pesquisa, foi realizado um estudo exploratório, dividido em três etapas: estudo do modelo eMAG, que é a base das avaliações; seleção dos repositórios, objetos de estudo; e, por fim, avaliação dos repositórios. Após esquadrinhar os repositórios públicos, verificou-se que eles não atendem todas as recomendações do próprio Governo Federal. Uma carta com sugestões e críticas construtivas foi remetida para cada um dos repositórios.

Palavras-Chave: Acessibilidade Digital, Pessoas com Deficiência Motora, Repositórios Educacionais Abertos.
\end{abstract}

\begin{abstract}
In the age of the information society, it has become imperative to consider the importance of actions aimed at digital accessibility as a way of dealing with the barriers that impact on the digital inclusion of people with disabilities. The purpose of this study is to evaluate two Open Educational Repositories, namely "Portal Dominio Público" and "Portal do Professor", to verify if they meet the recommendations of the eMAG - Accessibility Model in Electronic Government. In particular, only those recommendations concerning persons with motor disabilities are considered. In relation to the research method, an exploratory study was carried out, divided in three stages: study of the eMAG model, which is the basis of the assessment; selection of repositories, the objects of this study; and, finally, assessment of the repositories. It was verified that both repositories do not comply with all the recommendations of the Federal Government. A letter of suggestions and constructive criticism was sent to each of the repositories.
\end{abstract}

Keywords: Digital Accessibility, People with Motor Disabilities, Open Educational Repositories.

Cite as: Souza, E. \& Malheiros, N. (2018). Assessment of Digital Accessibility for People with Motor Disabilities in Open Educational Repositories (Avaliação de Acessibilidade Digital para Pessoas com Deficiência Motora em Repositórios Educacionais Abertos). Brazilian Journal of Computers in Education (Revista Brasileira de Informática na Educação - RBIE), 26(3), 01-19. DOI: 10.5753/RBIE.2018.26.03.1 


\section{Introdução}

A partir da década de 1980, com a introdução dos microprocessadores e a disseminação do uso dos computadores pessoais, seguida do advento da Internet comercial em 1990, que ganhou proporções mundiais, houve uma revolução em relação à criação e ao compartilhamento de informações e conhecimento. As Tecnologias de Informação e Comunicação (TICs) impactaram fortemente nosso cotidiano em diversos aspectos como: educação, entretenimento, prestação de serviços, capacitação profissional e inclusão social.

A Internet contribuiu fortemente para o fenômeno da globalização, como uma rede mundial de computadores interligando bilhões de pessoas que buscam acesso rápido a diversas possibilidades que atendam seus momentos de lazer e também necessidades profissionais. Em particular, no ambiente escolar, a Internet possibilitou a inserção de novas práticas pedagógicas, assim como facilitou o compartilhamento de recursos educacionais entre estudantes e professores. Como discutido em (Silva, 2012), as novas Tecnologias da Informação e Comunicação (TICs) são de fundamental importância, na sociedade moderna, por serem ferramentas significativas para o desenvolvimento de novas competências e habilidades, e, no contexto escolar, por propiciar novas formas de aprender, ensinar e produzir conhecimento.

Atualmente, verifica-se uma ampla difusão de repositórios abertos de mídias educacionais na Web. Como afirma Guedes et al. (2015), é evidente a relação desses repositórios com a democratização do conhecimento e sua aplicabilidade didática, com vistas ao uso e reuso de material oferecido abertamente aos educadores e estudantes. No entanto, há ainda uma parcela significativa da população excluída desses benefícios por várias razões. Existem diversas políticas públicas de inclusão digital com o objetivo de democratizar o acesso aos recursos disponíveis na Internet. Um aspecto muito importante na questão da inclusão digital é o desafio de viabilizar o acesso a esses recursos para as pessoas com necessidades especiais. Em particular, é de suma importância que indivíduos com deficiência motora tenham a seu favor ferramentas assistivas que lhe proporcionem inclusão digital e social e que atendam, dentro de suas limitações, suas expectativas como usuários autônomos das TICs.

No caso específico da Web, pode-se destacar o eMAG (Modelo de Acessibilidade em Governo Eletrônico), que é um conjunto de normas estabelecidas pelo Ministério do Planejamento, Orçamento e Gestão para regular a criação de sítios Web acessíveis (Freire et al., 2013). O modelo eMAG é um "conjunto de recomendações a ser considerado para que o processo de acessibilidade dos sítios e portais do governo brasileiro seja conduzido de forma padronizada e de fácil implementação" (eMAG Modelo de Acessibilidade em Governo Eletrônico, 2014). O eMAG inclui uma série de recomendações acerca da acessibilidade de indivíduos com necessidades especiais aos serviços e informações disponíveis na Web.

Mesmo com a obrigatoriedade de se considerar essas recomendações, muitos portais do Governo na Web não seguem os modelos estabelecidos (Silva \& Rue, 2015; Mezzaroba et al., 2016). Neste contexto, o objetivo deste trabalho é realizar uma avaliação de repositórios educacionais abertos criados pelo MEC, a saber, o Portal do Professor e o Portal Domínio Público, a fim de verificar se eles atendem às recomendações dispostas no Modelo eMAG 3.1, no que diz respeito à acessibilidade de pessoas com deficiência motora. Assim, o resultado esperado com este trabalho é contribuir para a inclusão digital de indivíduos com deficiência motora, a partir da navegação autônoma em repositórios educacionais de grande acesso.

Este artigo está organizado da seguinte forma. Na Seção 2, são apresentados os Repositórios Educacionais Abertos (REAs), suas características principais e suas múltiplas especificidades, considerando os repositórios "Portal do Professor" e "Portal Domínio Público" como objetos de estudo. Na Seção 3, são abordados conceitos sobre acessibilidade, incluindo aspectos como barreiras, tecnologias assistivas e uma breve descrição sobre o Modelo eMAG. 
$\mathrm{Na}$ Seção 4, descreve-se a metodologia utilizada neste trabalho. Na Seção 5, é apresentada a avaliação dos repositórios, incluindo um resumo comparativo com os resultados do trabalho. Por fim, na Seção 6, são apresentadas as considerações finais deste estudo.

\section{Repositórios Educacionais Abertos}

Conforme explicado em (Malheiros, 2014), os repositórios educacionais são sistemas computacionais desenvolvidos para armazenar objetos de aprendizagem de forma estruturada, e, assim, permitir que os usuários possam localizar, obter e compartilhar seus objetos de interesse.

Os repositórios educacionais abertos (REAs) têm por finalidade proporcionar ao usuário acesso a recursos educacionais sob domínio público ou licenças como a "Creative Commons". Esses repositórios oferecem suporte pedagógico para intervenção, formação continuada, espaço de pesquisa, troca de conhecimento, colaboração, objetos de aprendizagem e outros materiais pedagógicos diversos para consulta, modificação e livre compartilhamento.

Como apresentado em (Scheer \& Gama, 2004), os objetos educacionais são elementos das novas metodologias de ensino e aprendizagem baseadas no uso do computador e da Internet, que valorizam a criação de objetos e a sua reusabilidade para diversos contextos. A reusabilidade é uma das principais propriedades de objetos de aprendizagem, que garante um formato versátil para esses objetos de forma que eles possam ser compartilhados e modificados conforme a finalidade de seu uso, possivelmente, em diferentes contextos.

Neste trabalho, serão avaliados dois repositórios educacionais abertos mantidos pelo MEC: o "Portal do Professor" e o "Portal Domínio Público". As principais características desses repositórios são apresentadas a seguir. Porém, a discussão sobre a acessibilidade nesses repositórios é apresentada somente na Seção 5.

\subsection{Portal Domínio Público}

O Portal Domínio Público ${ }^{1}$ foi criado em 2004 pelo Ministério da Educação. O Portal especificamente é uma biblioteca digital que comporta várias obras literárias, artísticas e científicas, disponibilizadas ao público de forma gratuita.

O Portal Domínio Público é um repositório aberto de grande importância, sendo um espaço de divulgação e compartilhamento de obras que já se encontram em domínio público. Esse repositório abriga diversos tipos de objetos de aprendizagem, sendo um dos REAs mais populares.

\subsection{Portal do Professor}

O Portal do Professor ${ }^{2}$ foi criado pelo Ministério da Educação juntamente com o Ministério da Ciência e Tecnologia em 2008. Ele é um espaço que tem como objetivo apoiar, incentivar e assegurar ao professor subsídios para formação continuada. Além disso, esse Portal disponibiliza ferramentas para pesquisa, criação e compartilhamento de recursos pedagógicos.

De acordo com Bielschowsky e Prata (2010), o Portal do Professor veio para complementar de forma abrangente e nacional os portais governamentais estaduais, oferecendo uma gama de recursos que agregam e dão suporte aos professores como:

\footnotetext{
${ }^{1} \mathrm{http}: / / \mathrm{www}$.dominiopublico.gov.br

2 http://portaldoprofessor.mec.gov.br
} 
- Apoiar os cursos de capacitação do ProInfo Integrado;

- Oferecer aos professores um ambiente para que, após a conclusão do curso, sintamse incluídos em uma comunidade de pessoas que utilizam as TICs na educação;

- Disseminar experiências educacionais das diferentes regiões do Brasil;

- Oferecer recursos multimídia em diferentes formatos, assim como materiais de estudo, dicas pedagógicas, links para outros portais, ferramentas de autoria, dentre outros;

- Favorecer a interação para promover a reflexão crítica e as trocas de experiência entre professores de diferentes locais, formação e interesses;

- Oferecer um jornal eletrônico para atender a divulgação de eventos, ideias de educadores, bem como uma revista eletrônica que permite a professores exercerem, de forma crítica, a divulgação de suas ideias e experiências.

\section{Acessibilidade}

Acessibilidade é a capacidade de ação e movimento livres de quaisquer obstáculos ou entraves que impossibilitem a um indivíduo ter autonomia de seus atos, seja em espaços físicos ou virtuais. Conforme definido em (Decreto $\left.n^{\circ} 5.269,2004\right)$,

Art. 8o Para os fins de acessibilidade, considera-se:

I - acessibilidade: condição para utilização, com segurança e autonomia, total ou assistida, dos espaços, mobiliários e equipamentos urbanos, das edificações, dos serviços de transporte e dos dispositivos, sistemas e meios de comunicação e informação, por pessoa portadora de deficiência ou com mobilidade reduzida.

Muitos conceitos já foram formulados a respeito da acessibilidade e da sua importância para quebrar barreiras em qualquer setor da sociedade, a partir do uso de tecnologias assistivas, assim como dos benefícios da acessibilidade para facilitar ou tornar viável a interação do indivíduo com algum problema físico em qualquer âmbito. Este estudo aborda a questão da acessibilidade digital disponibilizada nos Repositórios Educacionais Abertos, em relação às pessoas com deficiência motora.

\subsection{Barreiras}

Existem diversas barreiras que comprometem o direito ao acesso completo a recursos digitais, de forma autônoma, pela pessoas com deficiência. Neste trabalho, considera-se as barreiras de comunicação conforme definição promulgada em (Decreto $\left.n^{0} 5.269,2004\right)$,

Art. 8o Para os fins de acessibilidade, considera-se:

II) barreiras: qualquer entrave ou obstáculo que limite ou impeça o acesso, a liberdade de movimento, a circulação com segurança e a possibilidade de as pessoas se comunicarem ou terem acesso à informação.

Portanto, as barreiras são impedimentos ou obstáculos que impossibilitam ou restringem o indivíduo de promover uma ação com autonomia quando do acesso a recursos digitais como sítios eletrônicos na Web. Essas barreiras coíbem o acesso e o compartilhamento de informações, bem como a interação e troca de experiências entre os indivíduos. Dessa forma, dificultam ou impedem o pleno acesso aos recursos disponíveis na Web, levando à exclusão digital e social da pessoa com deficiência.

De acordo com Queiroz (2008), entre as principais barreiras, no contexto de acessibilidade digital, podem-se destacar:

- atividades onde o tempo de utilização ou realização de uma tarefa é limitado; 
- navegadores e ferramentas que não possuem suporte para teclado alternativo ou botões correspondentes para os comandos efetuados por mouse;

- elementos de formulários que não podem ser acessados com a tecla “TAB” em uma sequência lógica.

De acordo com Freire et al. (2013), um dos principais entraves para a disseminação da cultura de acessibilidade na Web está na falta de conscientização dos profissionais de Tecnologia da Informação sobre a importância do tema.

\subsection{Tecnologias Assistivas}

As tecnologias assistivas são os instrumentos ou ferramentas que possibilitam autonomia e acessibilidade a pessoas com algum tipo de deficiência ou com mobilidade reduzida, em qualquer área de atuação na sociedade, com o objetivo de promover a inclusão desses indivíduos.

Existem ferramentas assistivas de baixo custo ou até mesmo gratuitas. Essas ferramentas podem ser componentes de hardware ou software. Em (Galvão Filho \& Damasceno, 2008), são destacados alguns exemplos de tecnologias assistivas:

- Hardware: adaptações nos teclados, máscara de teclados, suporte para textos, livros e outros, visando as necessidades específicas de cada indivíduo;

- Software: opções de acessibilidade do sistema operacional como, por exemplo, configuração do contraste das cores no monitor, simuladores de teclados e simuladores de mouse, etc.

Através desses recursos, diversas modificações podem ser feitas nas configurações do computador, adaptando-o a diferentes necessidades dos usuários. As opções de acessibilidade disponibilizadas pelo sistema operacional Windows, por exemplo, podem ser, desde a configuração das teclas numéricas (à direita do teclado) para que estas simulem comandos similares ao do mouse, até a configuração de teclas de aderência. Essas teclas foram criadas com a função de atender ao usuário que não consegue acionar duas teclas simultaneamente. As teclas de aderência podem ser habilitadas através das opções de Acessibilidade do Painel de Controle, conforme ilustrado na Figura 1.

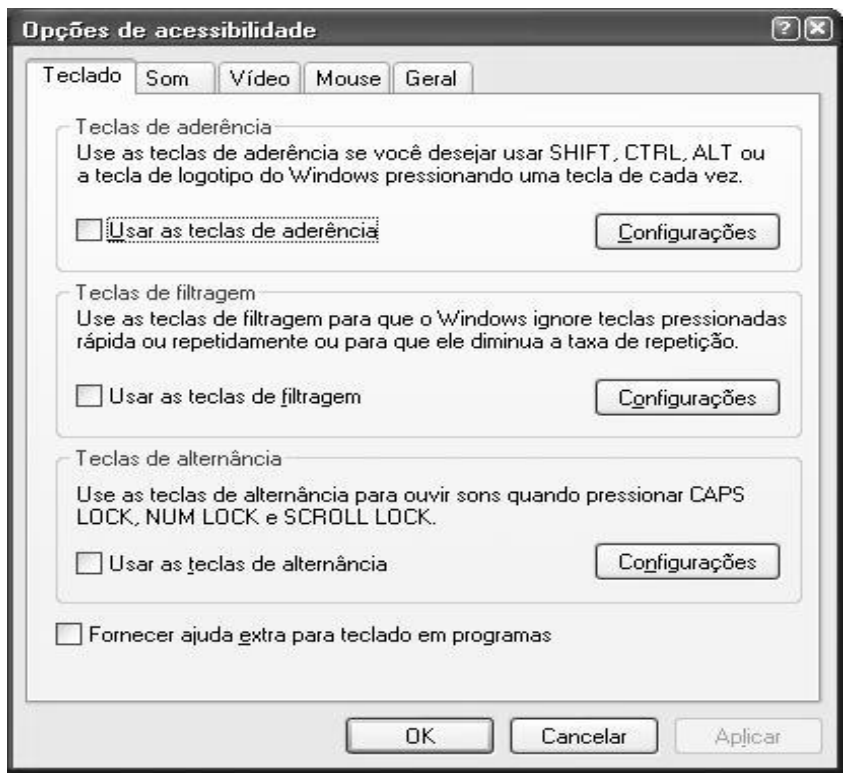

Figura 1: Opção de Acessibilidade - Teclas de Aderência. 


\subsection{Pessoa com Deficiência Motora}

De acordo com Silva (2012),

Considera-se, desse modo, "pessoa portadora de deficiência" todo aquele que apresentar perda ou anormalidade de uma estrutura ou função psicológica, fisiológica ou anatômica que gere incapacidade para o desempenho de atividade, dentro do padrão considerado normal para o ser humano. Para a proteção constitucional das pessoas portadoras de deficiência, considera-se o grau de deficiência que envolve a dificuldade de inclusão social [...].

A pessoa com deficiência motora é o indivíduo que possui limitações físicas decorrentes de fatores como perda de membros, paralisia parcial, ou outros problemas de ordem anatômica. Essa pessoa enfrenta barreiras impostas naturalmente por sua condição física no acesso às Tecnologias da Informação e Comunicação, por consequência, obstáculos que dificultam a execução de ações, de forma parcial ou total.

Ainda de acordo com Silva (2012), o indivíduo com deficiência tem seus direitos garantidos a partir da implementação de políticas de inclusão digital. Mas, para que isto ocorra, ele precisa ser assessorado adequadamente com tecnologias assistivas, permitindo que ele tenha a oportunidade de compartilhar e dar sua contribuição, partindo do princípio que todo indivíduo goza dos mesmos direitos na sociedade. Portanto, faz-se necessária uma investigação das barreiras que possam impedir o uso autônomo de recursos digitais pelos indivíduos com limitações motoras. Uma vez caracterizadas as barreiras, deve-se estudar e desenvolver tecnologias assistivas que possam promover a inclusão digital desses indivíduos.

França et al. (2005) discutem as principais dificuldades na criação de programas de computador com recursos de acessibilidade para pessoas com deficiência motora, inclusive considerando aspectos que não são de natureza técnica. Em geral, os principais dispositivos de entrada dos sistemas computacionais são o teclado e o mouse. Estes dispositivos exigem alto grau de coordenação motora e precisão no uso das mãos e dedos para acionar comandos ou realizar entrada de dados nos sistemas. Isso representa uma barreira para muitas pessoas com deficiência motora, pois elas podem ter dificuldade para realizar movimentos com precisão ou podem realizar movimentos de forma involuntária. Além disso, elas podem levar mais tempo para realizar certos movimentos e existem sistemas que impõem limites de tempo para realização de certas tarefas (por exemplo, para o preenchimento de formulários em aplicações Web).

Existem equipamentos para auxiliar pessoas, com limitações motoras nas mão ou dedos, no acionamento de comandos ou entrada de dados no computador. Esses equipamentos, em geral, envolvem próteses ou adaptações dos próprios dispositivos de entrada do computador. Em (Sonza et al., 2015), são apresentadas diversas tecnologias assistivas para pessoas com dificuldades motoras, como os teclados adaptados, colmeias, pulseiras de pesos, apontadores de cabeça, acionadores para mouse, simuladores de teclado ou programas que permitem que o usuário use comandos de voz para acionar os dispositivos de entrada.

Em geral, para um usuário com limitações motoras, é mais difícil usar o mouse que o teclado, devido ao nível de precisão exigido nos movimentos. Portanto, os programas de computador não devem restringir certos comandos ao uso do mouse, ou seja, deve existir uma alternativa para realizar a mesma tarefa utilizando-se o teclado. Além disso, a realização de uma tarefa deve exigir do usuário o número mínimo possível de movimentos a fim de facilitar o acesso aos recursos e evitar desconforto. 


\subsection{Modelo de Acessibilidade}

O projeto "Indicadores e Métricas para Avaliação de e-Serviços" foi desenvolvido pelo Ministério do Planejamento Orçamento e Gestão com o objetivo de avaliar a qualidade dos serviços públicos prestados por meios eletrônicos para o cidadão (Indicadores e métricas para avaliação de e-Serviços, 2007). Entretanto, sabe-se que diversos sítios governamentais na Web não atendem aos requisitos de acessibilidade propostos pelo próprio governo (Oliveira \& Eler, 2015). O trabalho de Freire et al. (2013) trata sobre o emprego de Métricas de acessibilidade como ferramenta de avaliação nos Sítios Web e, também, sobre a Legislação vigente no que diz respeito a acessibilidade digital.

O Modelo de Acessibilidade em Governo Eletrônico (eMAG) (eMAG Modelo de Acessibilidade em Governo Eletrônico, 2014) representa uma especificação de como promover acessibilidade nos sítios e portais do governo de forma padronizada. A última versão do modelo eMAG (versão 3.1) foi lançada em abril de 2014. A elaboração do modelo contou com profissionais especializados e também um processo de contribuições via consultas públicas. $\mathrm{O}$ propósito desse modelo é viabilizar o acesso de todos os indivíduos a informações e conteúdos disponíveis nos sítios e portais do Governo na Web. Além disso, esse modelo visa instruir os programadores através de um conjunto de recomendações quanto à criação de sítios acessíveis e a avaliação fundamentada conforme indicadores e métricas padronizados. De forma geral, as recomendações de acessibilidade do eMAG representam diretrizes que norteiam a criação de Sítios e portais do Governo, para viabilizar o acesso livre e sem barreiras aos conteúdos na Web para todas as pessoas.

O modelo eMAG especifica um total de 45 recomendações divididas em 6 áreas de acordo com as necessidades de criação e implementação dos sítios Web. As seis áreas são: Marcação, Comportamento, Conteúdo, Apresentação, Multimídia e Formulário.

Além disso, o modelo eMAG determina uma série de elementos padronizados de acessibilidade digital que devem estar presentes em todos os sítios do governo. Esses elementos são:

(i) Teclas de atalho;

(ii) Opção de alto contraste;

(iii) Barra de acessibilidade;

(iv) Apresentação do mapa do sítio;

(v) Descrição completa dos recursos de acessibilidade disponíveis.

Foi criado um sítio Web como modelo padrão com os elementos de acessibilidade digital. Esse modelo, ilustrado na Figura 2, inclui os cinco elementos padronizados de acessibilidade para orientar a criação de outros portais governamentais. 

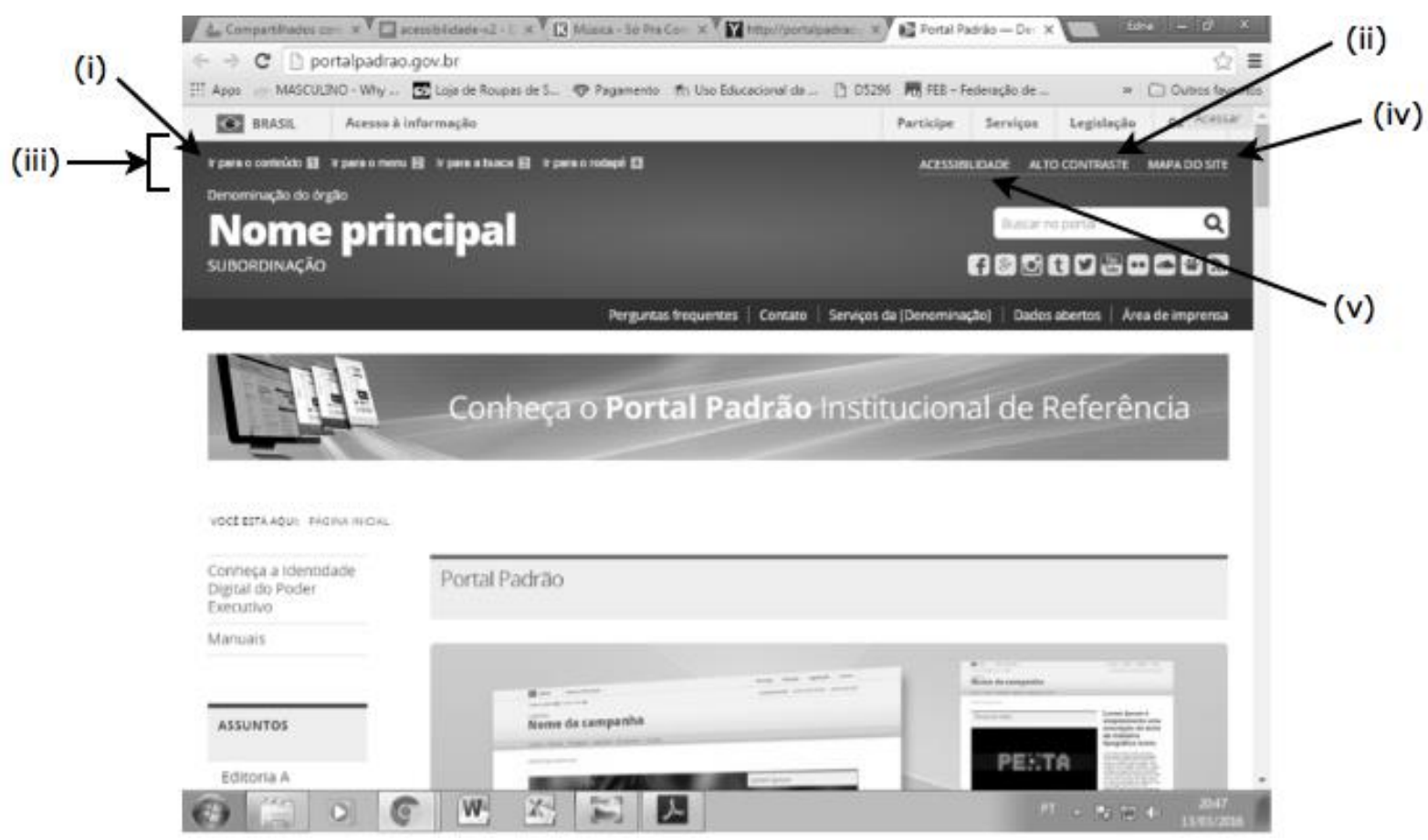

Figura 2: Portal padrão do Governo Federal com os elementos de acessibilidade.

\section{Metodologia}

Este trabalho representa uma atividade de pesquisa exploratória, que tem como objetivo principal avaliar repositórios educacionais abertos. Em cada portal Web, foi verificada a conformidade com as recomendações do modelo eMAG que afetam pessoas com deficiência motora, assim como o uso dos elementos padronizados. seguintes:

Este trabalho envolveu a realização das seguintes atividades, descritas nas subseções

1. Estudo do modelo eMag;

2. Seleção dos repositórios;

3. Avaliação dos repositórios.

\subsection{Estudo do Modelo eMAG}

Foi realizado um estudo sobre as recomendações do modelo eMAG. Entre as dezenas de diretrizes, foram selecionadas somente aquelas relacionadas à acessibilidade de pessoas com deficiência motora. As diretrizes foram selecionadas de acordo com a principais barreiras para pessoas com deficiência motora, conforme discutido na Seção 3.3. Para determinar se uma diretriz afeta pessoas com limitações motoras, foi verificado se o seu descumprimento resulta em:

A. restrição ao uso do mouse (as tarefas não podem ser realizadas pelo teclado);

B. aumento no número de movimentos que o usuário deve realizar (isso aumentaria o tempo para realização da tarefa e ainda geraria desconforto para o usuário);

C. limitação do tempo para realizar os movimentos (isso representa uma barreira crítica para usuários com limitações físicas e dificuldades de coordenação motora). 
As recomendações selecionadas para avaliação dos repositórios são apresentadas na Tabela 1. A última coluna da tabela relaciona cada recomendação a uma das três consequências indicadas discutidas.

Tabela 1: Recomendações eMAG selecionadas.

\begin{tabular}{|c|c|c|c|}
\hline Área & Número & Recomendação & Consequência \\
\hline \multirow{2}{*}{ Marcação } & 1.4 & $\begin{array}{c}\text { Ordenar de forma lógica e intuitiva a } \\
\text { leitura e tabulação. }\end{array}$ & $\mathrm{B}$ \\
\hline & 1.9 & $\begin{array}{c}\text { Não abrir novas instâncias sem a } \\
\text { solicitação do usuário. }\end{array}$ & B \\
\hline \multirow{4}{*}{ Comportamento } & 2.1 & $\begin{array}{c}\text { Disponibilizar todas as funções da página } \\
\text { via teclado. }\end{array}$ & $\mathrm{A}$ \\
\hline & 2.3 & $\begin{array}{l}\text { Não criar páginas com atualização } \\
\text { automática periódica. }\end{array}$ & $\mathrm{C}$ \\
\hline & 2.5 & $\begin{array}{l}\text { Fornecer alternativa para modificar } \\
\text { limites de tempo. }\end{array}$ & $\mathrm{C}$ \\
\hline & 2.7 & $\begin{array}{l}\text { Assegurar o controle do usuário sobre as } \\
\text { alterações temporais do conteúdo. }\end{array}$ & $\mathrm{B}, \mathrm{C}$ \\
\hline Conteúdo & 3.4 & $\begin{array}{c}\text { Informar o usuário sobre sua localização } \\
\text { na página. }\end{array}$ & B \\
\hline Apresentação & 4.3 & $\begin{array}{l}\text { Permitir redimensionamento sem perda de } \\
\text { funcionalidade. }\end{array}$ & $\mathrm{B}$ \\
\hline \multirow{2}{*}{ Formulário } & 6.3 & $\begin{array}{c}\text { Estabelecer uma ordem lógica de } \\
\text { navegação. }\end{array}$ & $\mathrm{B}$ \\
\hline & 6.4 & $\begin{array}{l}\text { Não provocar alteração no contexto } \\
\text { automaticamente. }\end{array}$ & $\mathrm{B}, \mathrm{C}$ \\
\hline
\end{tabular}

Além dessas recomendações, os elementos padronizados de acessibilidade digital do eMAG (explicados na Seção 3.4) também serão considerados na avaliação dos repositórios.

\subsection{Seleção dos Repositórios}

Entre os repositórios educacionais abertos criados pelo MEC, foram selecionados o "Portal do Professor" e o "Portal Domínio Público". Eles foram selecionados pela credibilidade, por serem portais sobre educação e por estarem entre os mais populares.

Outro fator preponderante desta seleção, é quantidade e qualidade dos objetos de aprendizagem, e recursos disponibilizados por estes portais, em variados formatos como imagens, artigos, obras, vídeos e outros, para serem compartilhados, usados e reutilizados, dando suporte educacional aos seus usuários.

\subsection{Avaliação dos Repositórios}

Os repositórios educacionais foram avaliados em relação à acessibilidade para pessoas com deficiência motora, considerando as recomendações selecionadas.

Conforme explicado em (Sonza et al., 2015), a avaliação de acessibilidade em portais Web pode ser feita de forma automática (por um software) ou de forma manual (por um ser humano). A validação automática traz muitos benefícios, mas, por mais sofisticados que sejam os verificadores automáticos, eles não podem substituir completamente a validação manual, pois alguns aspectos de acessibilidade só podem ser adequadamente avaliados por usuários reais. 
Neste trabalho, a avaliação foi feita de forma manual, sob a perspectiva de um usuário que acessa os serviços e documentos disponíveis em cada repositório. $\mathrm{O}$ navegador Web utilizado foi o Google Chrome ${ }^{3}$. O portal Web do repositório foi acessado para verificar se o mesmo atende ou não cada uma das recomendações do eMAG consideradas e, também, cada um dos elementos padronizados de acessibilidade. A finalidade foi verificar as recomendações atendidas pelos repositórios, assim como as ferramentas assistivas que eles utilizam para promover a acessibilidade digital a pessoas com deficiência motora.

Os resultados, apresentados na Seção 5, mostram quais recomendações são atendidas por cada repositório. Além disso, foram especificadas sugestões de melhorias para os repositórios avaliados. Essas sugestões, na forma de críticas construtivas, foram encaminhadas aos administradores dos repositórios.

\section{Resultados}

Os repositórios Portal Domínio Público e Portal do Professor são dois repositórios abertos que primam por qualidade, aceitação e credibilidade junto a seu diversificado grupo de usuários. Mas, conforme verificado neste estudo, esses usuários são atendidos apenas parcialmente em relação às recomendações do Modelo eMAG e aos elementos padronizados de acessibilidade digital, que também não são atendidos na sua totalidade.

A partir das avaliações realizadas, foi verificado que os repositórios precisam rever suas especificidades em relação à acessibilidade, assim como adequar o portal às recomendações e aos elementos padronizados de acessibilidade digital, para atender, de forma plena e efetiva, o indivíduo com deficiência motora.

Ambos os portais disponibilizam um canal de comunicação com o usuário, para dúvidas, sugestões e críticas. Assim, os problemas identificados e um série de sugestões foram encaminhadas aos administradores dos repositórios, a fim de relatar os diversos aspectos que não estão sendo respeitados em relação às diretrizes de acessibilidade do próprio Governo Federal.

\subsection{Avaliação do Portal Domínio Público}

A seguir, apresenta-se o resultado da avaliação do Portal Domínio Público, em relação a cada uma recomendações do modelo eMAG:

- A Recomendação 1.4 ("Ordenar de forma lógica e intuitiva a leitura e tabulação") foi atendida. Os elementos das páginas estão organizados de forma lógica e intuitiva, pois quando se usa a tecla "TAB" é possível mover o cursor entre os elementos da página na ordem/sequencia em que eles são apresentados na tela, de cima para baixo e da esquerda para a direita. Porém, nem todos os itens do formulário podem se alcançados pelo teclado. Por exemplo, ao preencher o formulário da página "Fale Conosco", ilustrado na Figura 5, se o cursor estiver no campo "Comentários" e for acionada a tecla "TAB", o cursor vai para o campo de endereço do navegador em vez de ir para o botão "Enviar" (que é o próximo elemento do formulário). No entanto, este problema de item não alcançado pelo teclado é tratado na Recomendação 2.1 , que foi considerada não atendida.

- A Recomendação 1.9 ("Não abrir novas instâncias sem a solicitação do usuário") foi atendida. Durante a navegação pelo conteúdo do portal, não são abertas novas janelas ou abas do navegador, a não ser por comando do próprio usuário.

${ }^{3}$ https://www.google.com.br/intl/pt-BR/chrome/browser 
- A Recomendação 2.1 ("Disponibilizar todas as funções da página via teclado") não foi atendida. Não é possível mover-se pelo teclado por todos os elementos da página sem acessar o mouse. Por exemplo, na página principal do portal, não é possível é possível acionar o botão "Pesquisa" sem usar o mouse. Esse botão não é alcançável pela navegação utilizando-se apenas o teclado. Muitos itens do menu também só são acessíveis através do mouse.

- A Recomendação 2.3 ("Não criar páginas com atualização automática periódica") foi atendida. As páginas do portal não são recarregadas automaticamente.

- A Recomendação 2.5 ("Fornecer alternativa para modificar limite de tempo") foi considerada atendida, uma vez que nas páginas do portal não há limite de tempo para realizar qualquer tarefa.

- A Recomendação 2.7 (“Assegurar o controle do usuário sobre as alterações temporais do conteúdo") foi considerada atendida pois o portal não apresenta conteúdos que exijam controle sobre o tempo de exibição.

- A Recomendação 3.4 ("Informar o usuário sobre sua localização na página") não foi atendida. $O$ Portal não disponibiliza para o usuário sua localização sequencial na página navegada; não é apresentado o caminho percorrido na estrutura da portal.

- A Recomendação 4.3 ("Permitir redimensionamento sem perda de funcionalidade") não foi atendida. Quando a página é redimensionada, o layout não é reajustado, de forma que alguns elementos do menu não podem ser mais vistos e aparece uma barra de rolagem horizontal. O deslocamento da barra de rolagem é um movimento que exige precisão e, portanto, representa um barreira para pessoas com deficiência motora. $\mathrm{Na}$ Figuras 3 e 4, é apresentado um exemplo desse problema na página de pesquisa. As figuras mostra a mesma tela, antes (Figura 3) e depois (Figura 4) de ser redimensionada. Pode-se notar que, para ver os itens formulário de pesquisa na parte superior da tela, o usuário precisaria usar a barra de rolagem. O layout da página deveria ser ajustado automaticamente para que isso não acontecesse.

- A Recomendação 6.4 ("Não provocar alteração no contexto automaticamente") foi atendida. Não acontecem mudanças automáticas nas páginas, quando um elemento de algum formulário recebe o foco.

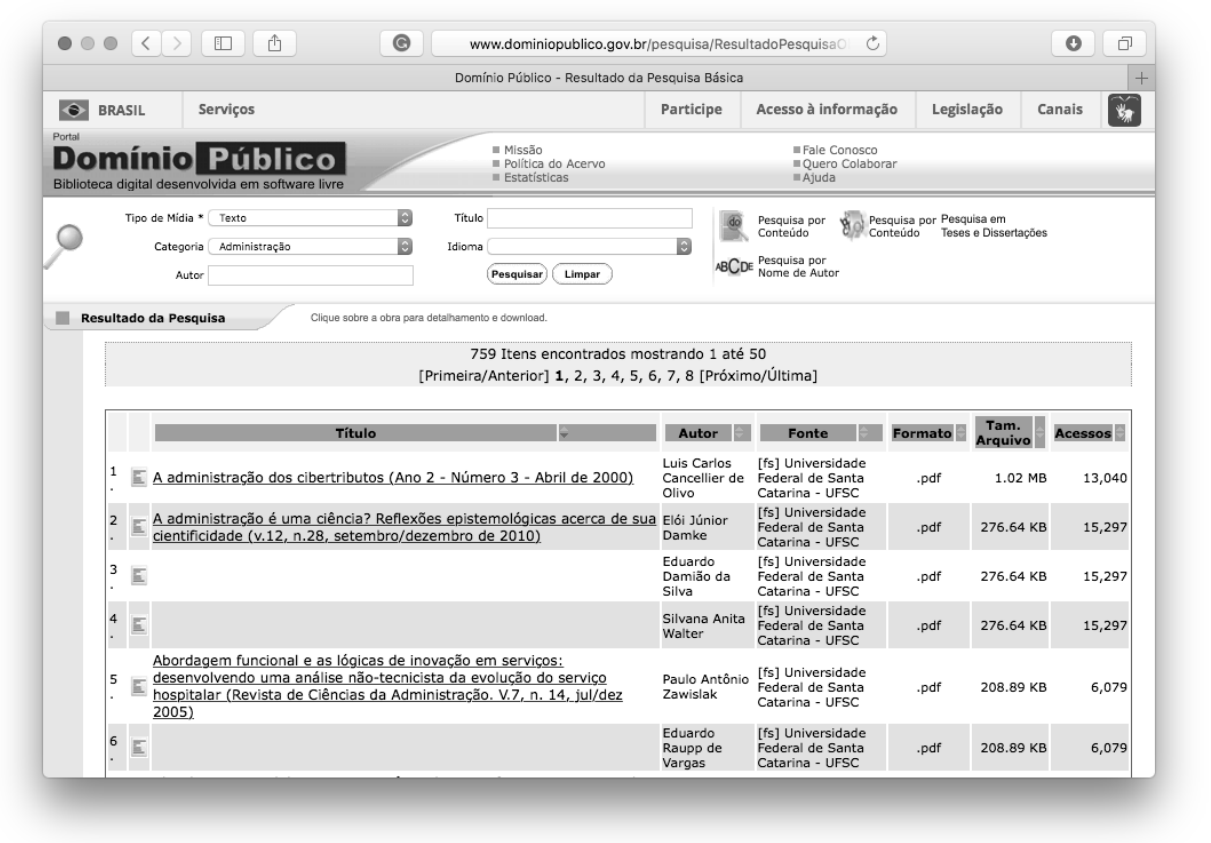

Figura 3: Página de pesquisa antes do redimensionamento. 


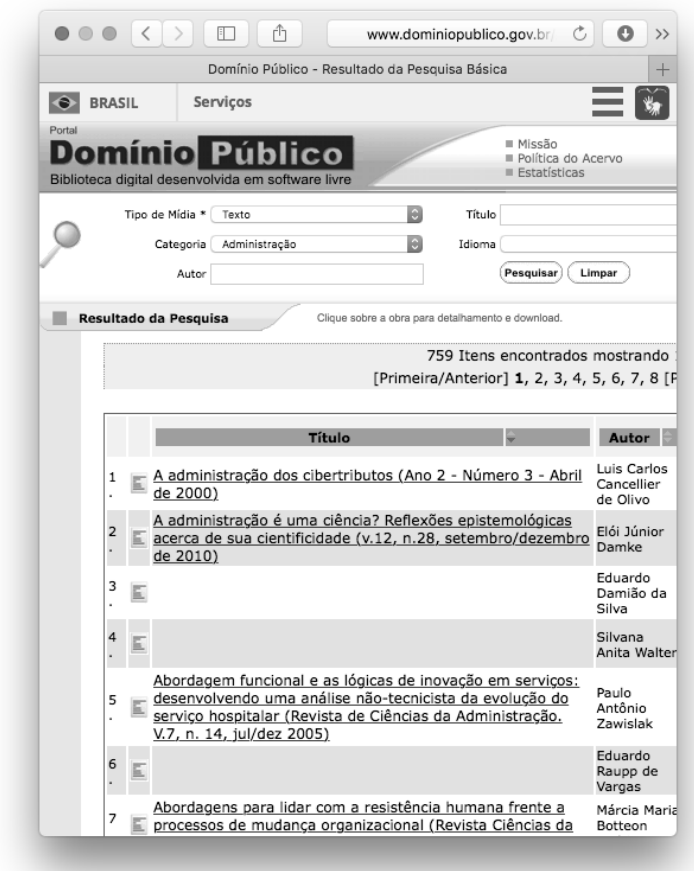

Figura 4: Página de pesquisa depois do redimensionamento.

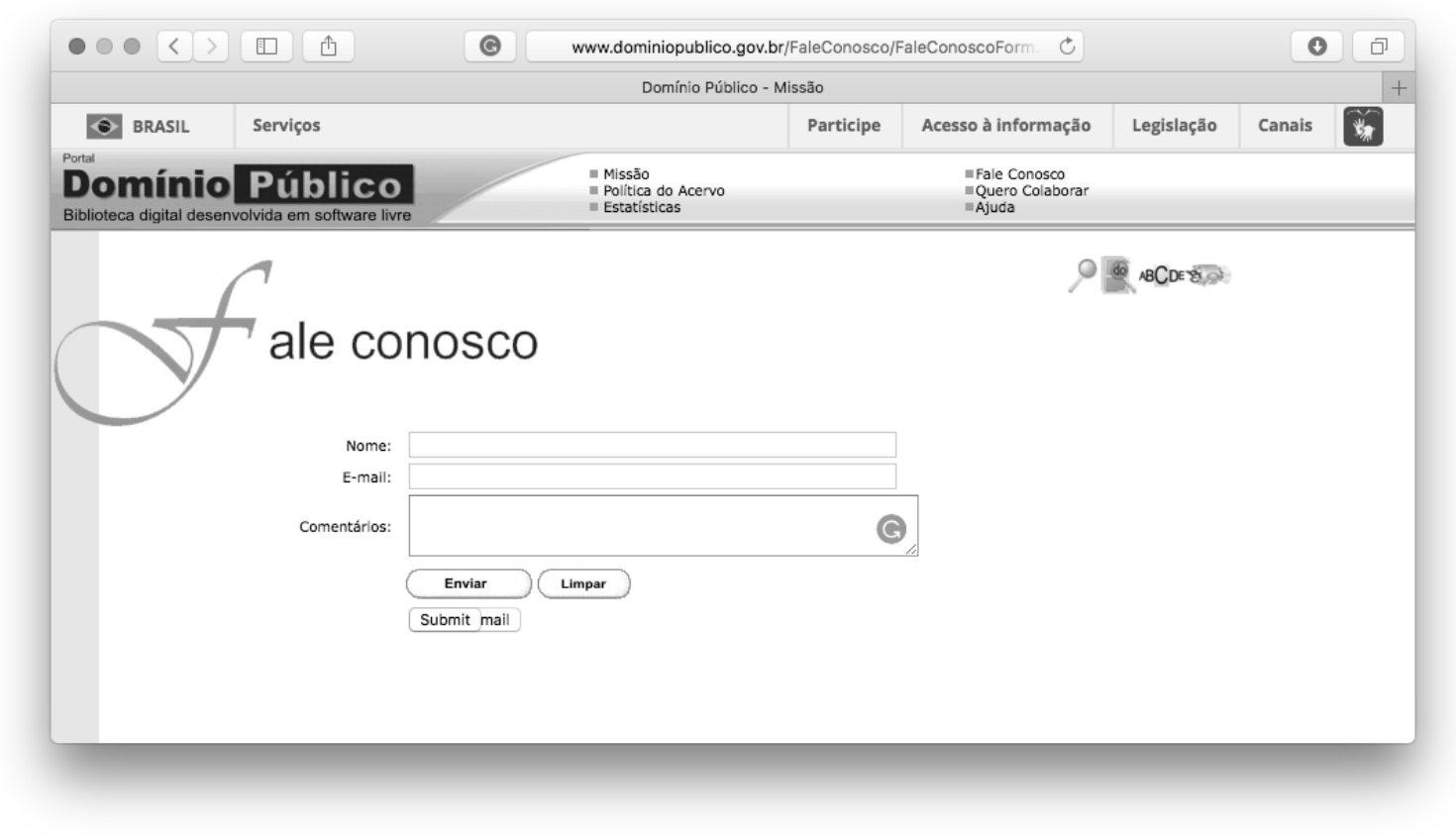

Figura 5: Página da seção "Fale Conosco” no Portal Domínio Público.

Verificou-se que o Portal Domínio Público cumpre a maioria das recomendações consideradas, indicando um tentativa na questão de promover acessibilidade digital ao usuário. Não ocorreu o cumprimento de três recomendações: disponibilizar todas as funções da página via teclado (2.1); informar ao usuário sua localização na página (3.4); e permitir redimensionamento sem perda de funcionalidade (4.3). Essas faltas podem comprometer o 
acesso do usuário com deficiência motora, inviabilizando sua navegação, com autonomia, nas páginas Web do repositório.

Em relação aos elementos padronizados de acessibilidade, foi verificado que o repositório Portal Domínio Público não cumpre todas as exigências. Na página principal do portal, não há uma opção para habilitar alto contraste de cores, mapa do site, barra de acessibilidade ou descrição completa dos recursos de acessibilidade disponíveis. Isso pode ser verificado na página principal do portal como ilustrado na Figura 6.

O Portal Domínio Público, apesar de ser um repositório de grande credibilidade, precisa rever a questão da acessibilidade digital disponibilizada em seu portal para atender indivíduos com deficiência motora. A falta de tecnologias assistivas e o não cumprimento das diretrizes de forma completa acabam por limitar a autonomia desses indivíduos no acesso aos recursos e serviços disponíveis no portal.

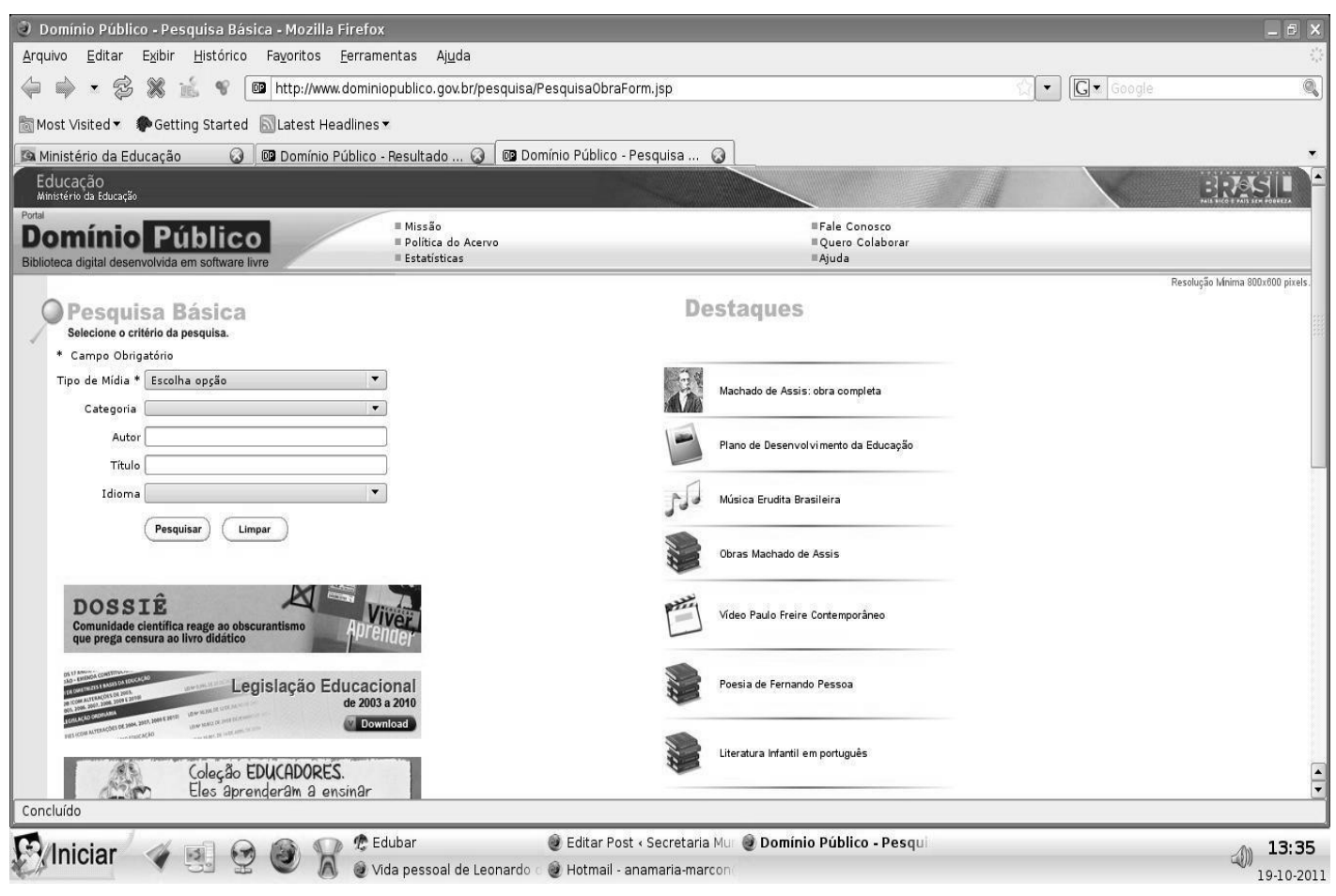

Figura 6: Página principal do Portal Domínio Público.

\subsection{Avaliação do Portal do Professor.}

A seguir, apresenta-se o resultado da avaliação do Portal do Professor, em relação a cada uma recomendações do modelo eMAG:

- A Recomendação 1.4 ("Ordenar de forma lógica e intuitiva a leitura e tabulação") foi atendida. Os elementos das páginas estão organizados de forma lógica e intuitiva, pois quando se usa a tecla "TAB" é possível mover o cursor entre os elementos da página na ordem/sequencia em que eles são apresentados na tela, de cima para baixo e da esquerda para a direita. No entanto, este problema de item não alcançado pelo teclado é tratado na Recomendação 2.1, que foi considerada não atendida.

- A Recomendação 1.9 ("Não abrir novas instâncias sem a solicitação do usuário") foi atendida. Durante a navegação pelo conteúdo do portal, não são abertas novas janelas ou abas do navegador, a não ser por comando do próprio usuário. 
- A Recomendação 2.1 ("Disponibilizar todas as funções da página via teclado") não foi atendida. Não é possível mover-se pelo teclado por todos os elementos da página sem acessar o mouse. Na página principal do portal, não é possível acessar via teclado todos os itens da página, por exemplo, os itens do menu na parte superior, como ilustrado na Figura 7. Esses itens do menu só são acessíveis através do mouse.

- A Recomendação 2.3 ("Não criar páginas com atualização automática periódica") foi atendida. As páginas do portal não são recarregadas automaticamente.

- A Recomendação 2.5 ("Fornecer alternativa para modificar limite de tempo") foi considerada atendida, uma vez que nas páginas do portal não há limite de tempo para realizar qualquer tarefa.

- A Recomendação 2.7 (“Assegurar o controle do usuário sobre as alterações temporais do conteúdo") não foi atendida. Na página principal, não existe controle sobre o tempo de exibição das imagens que se sucedem para anunciar as notícias em destaque no portal. Como ilustrado na Figura 7, o portal tem um espaço para notícias em destaque. $\mathrm{Na}$ figura, a notícia em destaque é "Conteúdo em Português para o Ensino Fundamental". Esse destaque é alterado periodicamente. Neste caso, três notícias se alternam no espaço de destaque. Um usuário pode usar o mouse para escolher uma notícia, para isso basta clicar no número da notícia que se encontra no canto superior direito do espaço da notícia. Mas, o usuário não consegue fazer isso via teclado, nem controlar o tempo que o conteúdo da notícia permanece na tela. Esse tempo pode ser curto para que uma pessoa com deficiência motora consiga clicar na notícia.

- A Recomendação 3.4 ("Informar o usuário sobre sua localização na página") foi atendida. $\mathrm{O}$ portal mostra a trajetória sequencial da navegação, permitindo ao usuário identificar sua localização na estrutura do conteúdo do portal. Por exemplo, ao clicar na opção "Criar Aula" no item de menu "Espaço da Aula", a página para a qual o usuário é direcionado mostra a localização do usuário na estrutura de navegação, como destacado na Figura 8.

- A Recomendação 4.3 ("Permitir redimensionamento sem perda de funcionalidade") não foi atendida. Quando a página é redimensionada, o layout não é reajustado, de forma que alguns elementos do menu e dos campos de login e busca não podem ser mais visto. Esses elementos deveriam ser reposicionados para continuarem visíveis na tela, por exemplo, logo abaixo da notícia em destaque. Porém, isso não acontece, como ilustrado na Figura 9.

- A Recomendação 6.4 ("Não provocar alteração no contexto automaticamente") foi atendida. Não acontecem mudanças automáticas nas páginas, quando um elemento de algum formulário recebe o foco. 


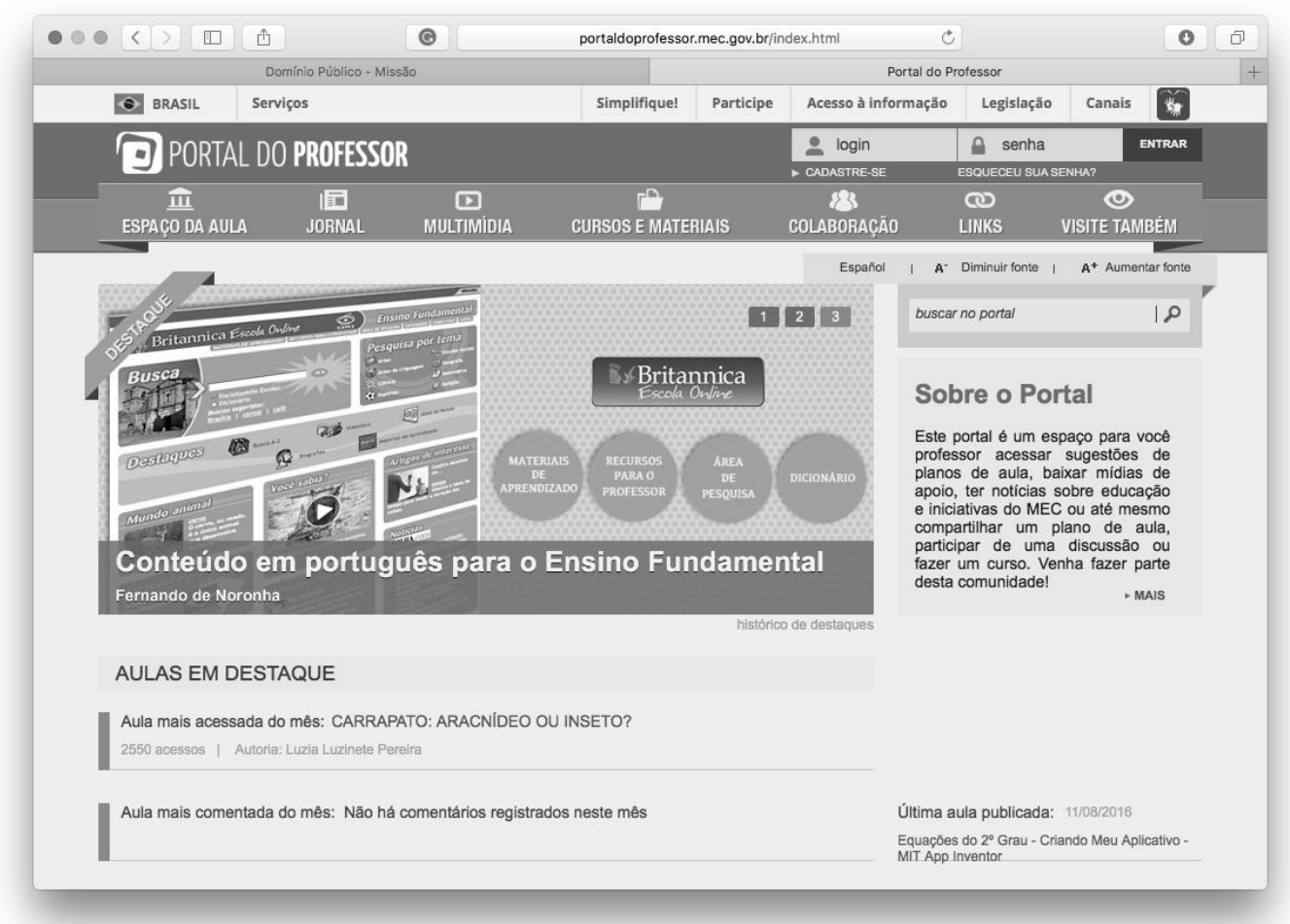

Figura 7: Página principal do Portal do Professor.

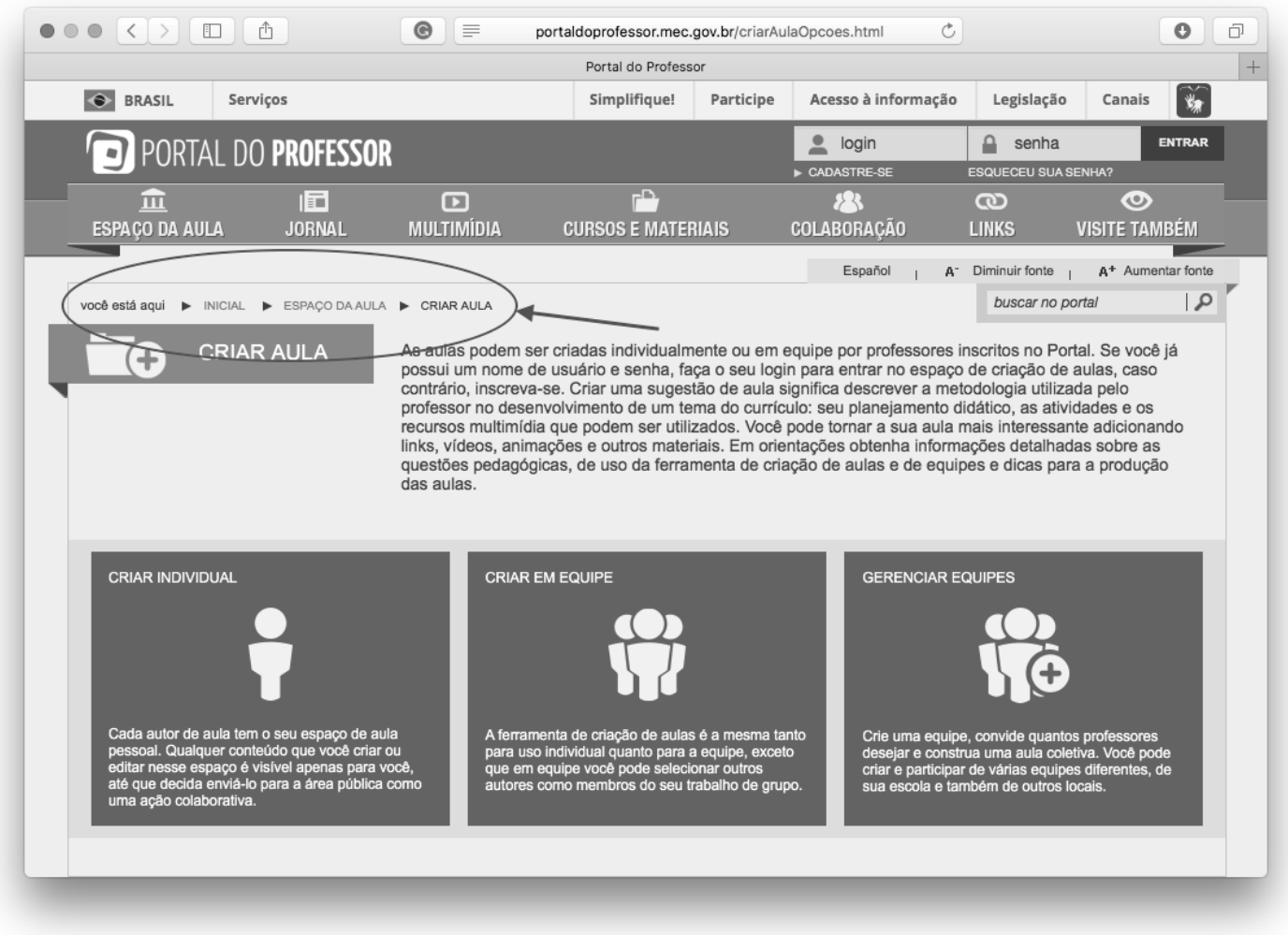

Figura 8: Exibição da localização do usuário na estrutura de navegação do portal. 


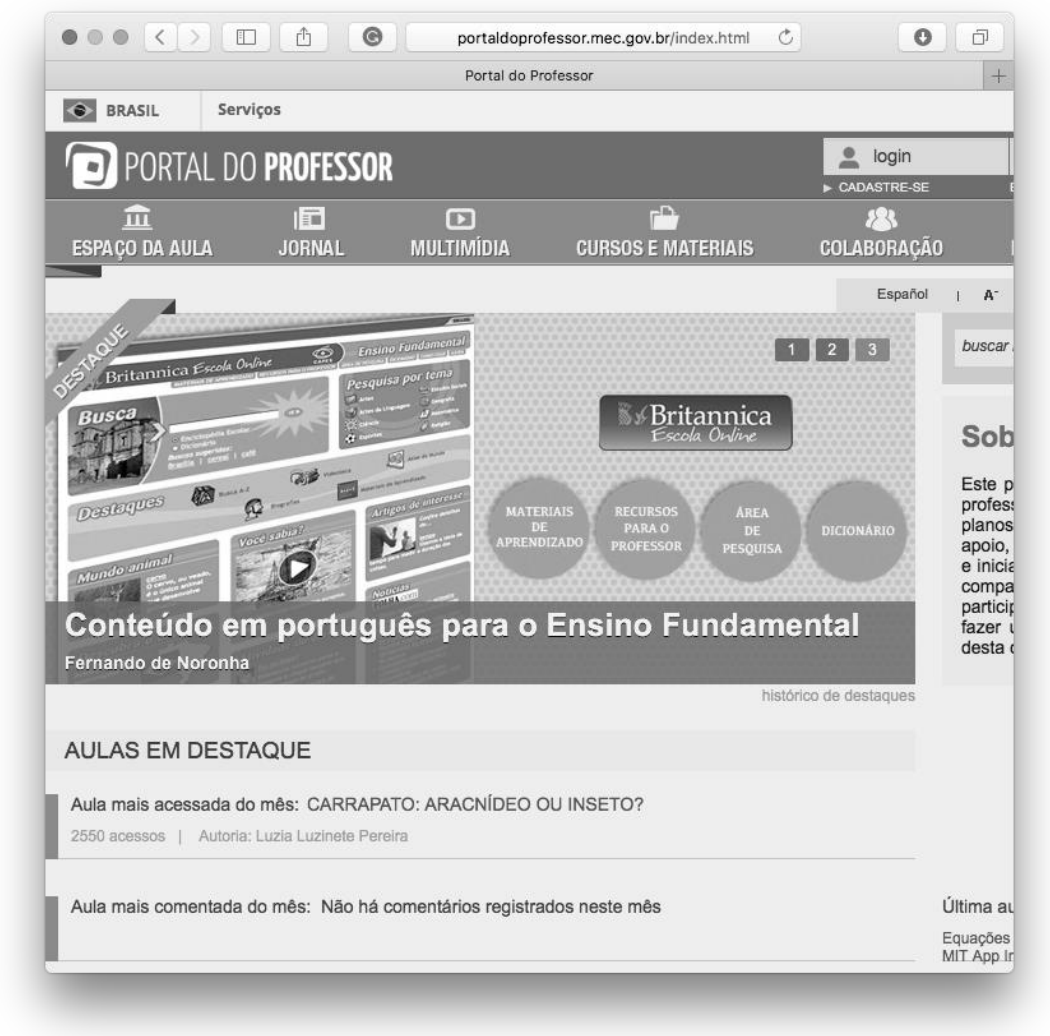

Figura 9: O layout da não é reajustado na página principal do Portal do Professor.

O repositório Portal do Professor segue a maioria das recomendações de acessibilidade consideradas. No entanto, esta avaliação permitiu constatar falta de conformidade em relação a três recomendações: disponibilizar todas as funções da página via teclado (2.1); assegurar o controle do usuário sobre as alterações temporais do conteúdo (2.7); e permitir redimensionamento sem perda de funcionalidade (4.3). Essas falhas em relação às diretrizes de acessibilidade comprometem a navegação autônoma de indivíduos com deficiência motora.

Em relação aos elementos padronizados de acessibilidade, foi verificado que o repositório Portal do Professor não cumpre todas as exigências. Na página principal do portal, não há opção de habilitar alto contraste de cores, barra de acessibilidade ou descrição completa dos recursos de acessibilidade. Isso pode ser observado na página principal do portal ilustrada na Figura 7. O único elemento de acessibilidade disponível é o mapa do site, mas, esse elemento está disponível no rodapé da página $\mathrm{Web}$, o que não é apropriado. O elemento deveria estar na parte superior da página conforme modelo explicado na Seção 3.4.

Da mesma forma que o repositório Portal Domínio Público, o Portal do Professor deixa de cumprir diretrizes fundamentais para garantia da acessibilidade. Consequentemente, a ausência de boas práticas de acessibilidade digital resulta em barreiras que impedirão diversos usuários com deficiência motora de navegar com autonomia no portal Web desses repositórios tão importantes. 


\subsection{Resumo Comparativo}

$\mathrm{Na}$ Tabela 4, é apresentado um comparativo geral entre os repositórios educacionais avaliados. Essa tabela mostra quais recomendações foram atendidas $(\checkmark)$ ou não $(\boldsymbol{X})$.

Tabela 2: Resumo comparativo da avaliação dos repositórios.

\begin{tabular}{|c|c|c|c|}
\hline & Recomendação & Portal Domínio Público & Portal do Professor \\
\hline 1.4 & $\begin{array}{c}\text { Ordenar de forma lógica e intuitiva a } \\
\text { leitura e tabulação. }\end{array}$ & $\checkmark$ & $\checkmark$ \\
\hline 1.9 & $\begin{array}{c}\text { Não abrir novas instâncias sem a } \\
\text { solicitação do usuário. }\end{array}$ & $\checkmark$ & $\checkmark$ \\
\hline 2.1 & $\begin{array}{c}\text { Disponibilizar todas as funções da página } \\
\text { via teclado. }\end{array}$ & $\checkmark$ & $\checkmark$ \\
\hline 2.3 & $\begin{array}{c}\text { Não criar páginas com atualização } \\
\text { automática periódica. }\end{array}$ & $\checkmark$ & $\checkmark$ \\
\hline 2.5 & $\begin{array}{c}\text { Fornecer alternativa para modificar limite } \\
\text { de tempo. }\end{array}$ & $\checkmark$ & $\checkmark$ \\
\hline 2.7 & $\begin{array}{c}\text { Assegurar o controle do usuário sobre as } \\
\text { alterações temporais do conteúdo. }\end{array}$ & $\mathbf{X}$ & $\mathbf{X}$ \\
\hline 3.4 & $\begin{array}{c}\text { Informar o usuário sobre sua localização } \\
\text { na página. }\end{array}$ & $\checkmark$ & $\checkmark$ \\
\hline 4.3 & $\begin{array}{c}\text { Permitir redimensionamento sem perda } \\
\text { de funcionalidade. }\end{array}$ & $\checkmark$ \\
\hline 6.4 & $\begin{array}{c}\text { Não provocar alteração no contexto } \\
\text { automaticamente. }\end{array}$ & & $\checkmark$ \\
\hline
\end{tabular}

O principais problemas, que afetam ambos os repositórios, são: a impossibilidade de navegar somente com o teclado (dispensando a coordenação motora de precisão exigida pelo uso do mouse), a falta de reposicionamento dos elementos das páginas quando elas são redimensionadas e a ausência da maioria dos elementos padronizados de acessibilidade.

Verifica-se portanto uma série de problemas de acessibilidade nesses dois repositórios educacionais criados pelo MEC. Esses problemas precisam ser corrigidos para que se possa promover a inclusão de pessoas com deficiência motora.

\section{Conclusão}

Tendo em vista os aspectos observados nos repositórios educacionais abertos, no que diz respeito à acessibilidade, constatou-se alguns problemas que precisam ser sanados. O portal Web de cada repositório foi acessado a partir do navegador Web Google Chrome, para avaliação manual de suas características e funcionalidades em relação à acessibilidade digital.

Percebemos que o Portal Domínio Público e o Portal do Professor atendem apenas parcialmente as recomendações do eMAG. Além disso, esses repositórios devem atentar também para os elementos padronizados de Acessibilidade Digital que não constam no cabeçalho da página principal dos portais. Portanto, é imprescindível que esses repositórios sejam adequados às diretrizes de acessibilidade digital vigentes no Modelo eMAG, para sanar as barreiras que possam afetar a autonomia de navegação dos usuários com deficiência motora.

Espera-se que este estudo possa contribuir para que as mudanças necessárias possam ser realizadas no portal Web dos repositórios, viabilizando a inclusão digital de pessoas com deficiência motora. Para isso, foram enviadas sugestões e críticas construtivas para os repositórios Portal Domínio Público e Portal do Professor, com o intuito de informar sobre as adequações necessárias em relação à acessibilidade digital. 
Além disso, apesar deste trabalho ter avaliado alguns repositórios específicos, as questões levantadas são comuns em diversos recursos digitais disponíveis na Web. Assim, este trabalho é importante também para conscientizar, de forma geral, os profissionais responsáveis pela gestão de sítios e aplicações na Web, sobre cuidados necessários para se garantir acessibilidade desses recursos a pessoas com deficiência motora.

Como trabalho futuro, pretende-se avaliar outros repositórios educacionais e também investigar e propor correções e soluções de tecnologias assistivas para os portais que não atendem às recomendações de forma plena. Além disso, uma questão muito importante seria avaliar os repositórios a partir de testes com pessoas com deficiência motora.

\section{Agradecimentos}

Os autores gostariam de agradecer ao Prof. André Pimenta do Departamento de Ciência da Computação da UFLA e à Diretoria de Educação à Distância (DIRED) da UFLA pelo grande apoio ao desenvolvimento deste trabalho.

\section{Referências}

Bielschowsky, C. E., \& Prata, C. E. (2010). Portal Educacional do Professor do Brasil. Revista de Educación, 352, 617-637. Disponível em http://www.revistaeducacion.educacion.es/re352/re352 28.pdf

BRASIL. (2004). Decreto $n^{o} 5.269$, de 2 de dezembro de 2004. Regulamenta as Leis nos 10.048 , de 8 de novembro de 2000, que dá prioridade de atendimento às pessoas que especifica, e 10.098, de 19 de dezembro de 2000, que estabelece normas gerais e critérios básicos para a promoção da acessibilidade das pessoas portadoras de deficiência ou com mobilidade reduzida, e dá outras providências. Diário Oficial, Brasília, DF, 4 de dezembro de 2004. Seção 1, p. 5.

BRASIL. (2007). Ministério do Planejamento, Orçamento e Gestão. Secretaria de Logística e Tecnologia da Informação. Indicadores e métricas para avaliação de e-Serviços. Brasília : MP. Disponível em https://www.governoeletronico.gov.br/documentos-earquivos/LivroFina 04102007.pdf/at_download/file

BRASIL. (2014). Ministério do Planejamento, Orçamento e Gestão. Secretaria de Logística e Tecnologia da Informação. eMAG Modelo de Acessibilidade em Governo Eletrônico. Brasília : MP, SLTI. Disponível em https://www.governoeletronico.gov.br/documentos-earquivos/eMAGv31.pdf

França, C. R., Borges, J. A., \& Sampaio, F. F. (2005, Novembro). Tupi - Recursos de acessibilidade para educação especial e inclusiva dos deficientes motores. Simpósio Brasileiro de Informática na Educação-SBIE, vol. 1, no. 1, pp. 591-600. Disponível em: http://br-ie.org/pub/index.php/sbie/article/view/443

Freire, A. P., Bettio, R. W., Frade, E. G., Ferrari, F. B., Monserrat Neto, J., \& Libardi, H. (2013) Acessibilidade de conteúdo multimídia e Web: técnicas e exemplos do contexto educacional. In Tópicos em Multimídia, Hipermídia e Web. Editora da Sociedade Brasileira de Computação.

Galvão Filho, T. A., \& Damasceno, L. L. (2008) Tecnologia Assistiva em Ambiente Computacional: Recursos para Autonomia e Inclusão Socio-digital da Pessoa com 
Deficiência. In Boletín del Real Patronato Sobre Discapacidad (pp. 14-23), Ministerio de Educación, Política Social y Deporte, Madri, Espanha.

Guedes, J. T., Gonçalves, H. A., \& Nascimento, M. B. C. (2015). Recursos Educacionais Abertos: Significados na Prática Docente. In Atas do 4o Congresso Ibero-Americano em Investigação Qualitativa (pp. 528-532), Aracajú, Brasil.

Malheiros, N. Repositórios Educacionais na Web. 1.ed. Lavras: UFLA, 2014.

Mezzaroba, M. P., Almeida, T. C. de, Ulbricht, V. R., Vanzin, T., \& Fadel, L. M. (2016). Acessibilidade em portais de Governo Eletrônico do Poder Judiciário, Revista Brasileira de Design da Informação, 13, 93-104.

Oliveira, A. D. A., \& Eler, M. M. (2015). Acessibilidade em governo eletrônico: um estudo sobre a aplicação de padrões Web em sítios gov.br. XI Simpósio Brasileiro de Sistemas de Informação, 683-690. Disponível em: http://www.each.usp.br/marceloeler/papers/OliveiraEler-SBSI2015.pdf. [GS Search]

Queiroz, M. A. (2008). Acesso à Web e Tecnologias Assistivas. Disponível em http://www.acessibilidadelegal.com/33-acesso.php.

Scheer, S., \& Gama, C. L. G. (2004). Construção de um repositório para objetos educacionais hipermídia. In Congresso Nacional de Ambientes Hipermídia para Aprendizagem, Florianópolis, Brasil.

Silva, L. G. da (2012). Portadores de deficiência, igualdade e inclusão social. Princípio: a Dignidade da Pessoa Humana. Ambito Jurídico, 99. Disponível em: http://www.ambitojuridico.com.br/site/?n_link=revista_artigos_leitura\&artigo id=11413.

Silva, R. L. da, \& Rue, L. A. de la. (2015). A acessibilidade nos sites do Poder Executivo estadual à luz dos direitos fundamentais das pessoas com deficiência, Revista de Administração Pública, 49, 315-336. Disponível em: http://bibliotecadigital.fgv.br/ojs/index.php/rap/article/view/46630

Sonza, A. P., Conforto, D., \& Santarosa, L. (2015). Acessibilidade nos portais da educação profissional e tecnológica do Ministério da Educação. Revista Brasileira da Educação Profissional e Tecnológica, 1(1), 131-145. Disponível em: http://www2.ifrn.edu.br/ojs/index.php/RBEPT/article/viewFile/2874/pdf 11. [GS Search] 